\title{
How to Improve Properties of Nickel-Titanium Rotary Instruments
}

\author{
Gianluca Gambarini ${ }^{1}$, Gabriele Miccoli ${ }^{2}$, Alessio Zanza ${ }^{3}$, Andrea Del Giudice ${ }^{4}$, Luca Testarelli ${ }^{5}$
}

The Journal of Contemporary Dental Practice (2020): 10.5005/jp-journals-10024-2796

In the last decades, the use of nickel-titanium ( $\mathrm{Ni}-\mathrm{Ti}$ ) rotary instruments has become the most effective and popular method among endodontists for shaping root canals, even if there are still concerns regarding the increased risks of intracanal breakage or weakening of the instruments. ${ }^{1,2}$ So manufacturers started to modify the cross-sectional geometrical aspects of the files in order to improve their resistance to torsional and cyclic fatigue. Design is a major feature in determining instruments' properties including cutting efficiency, removal of debris, stresses generated during instrumentation, and the relative resistance to these stresses; however, a perfect design is not existing and any change in design is likely to provide some advantages but also some disadvantages. ${ }^{3,4}$

More recently, another strategy to improve properties was the development of new manufacturing processes to optimize the microstructure of $\mathrm{Ni}-\mathrm{Ti}$, basically through innovative thermomechanical processing. For example, M-wire, CM wire, twisted files, and firewire instruments showed an enhanced flexibility and resistance to flexural stress when compared to the nontreated Ni-Ti alloys. ${ }^{5}$ Unfortunately, all these treatments are not disclosed by manufacturers and only the final results on the instruments' performance can be tested. Firewire technology has shown the most promising results by significantly improving the above-mentioned properties without negatively affecting the torsional resistance of the instruments. ${ }^{6}$ Nowadays clinicians can prebend martensitic (ductile) Ni-Ti rotary files if needed, while in the past only superelastic (austenitic) instruments were available; all these features are currently used in clinical practice to facilitate insertion and progression inside complex curvature, divergent canals, and in bypassing ledges. Moreover, instruments' elastic return and the consequent risk of canal transportation is reduced when martensitic instruments are used., ${ }^{7,8}$

A third factor has become important in the clinical performance of the instruments: the use of different motions, due to the introduction of new open motors which provide the possibility of selecting or modifying motions and parameters (usually reciprocating motion instead of or together with continuous rotation). It has been demonstrated that the resistance to torsional and cyclic fatigue can also be enhanced by using different types of reciprocating motion: this can improve instrument's resistance to the different stresses when compared with traditional continuous rotation. New techniques alternating the use of different motions for the same instruments are currently being developed to improve safety without negatively affecting efficiency. On the contrary, different motions do not affect the flexibility of the $\mathrm{Ni}-\mathrm{Ti}$ instruments. 9,10

Apart from the above-mentioned features which are depending on manufacturers' products, there are other clinical

\author{
${ }^{1-5}$ Department of Oral and Maxillofacial Sciences, Sapienza University \\ of Rome, Italy \\ Corresponding Author: Luca Testarelli, Department of Oral and \\ Maxillofacial Sciences, Sapienza University of Rome, Italy, Phone: +39 \\ 3381504 134, e-mail: luca.testarelli@uniroma1.it \\ How to cite this article: Gambarini G, Miccoli G, Zanza A, et al. How to \\ Improve Properties of Nickel-Titanium Rotary Instruments. J Contemp \\ Dent Pract 2020;21(4):351-352. \\ Source of support: Nil \\ Conflict of interest: None
}

factors that could significantly affect both instrumentation stresses and mechanical resistance of $\mathrm{Ni}-\mathrm{Ti}$ instruments: the anatomic challenges, the operator's skills, the preparation of a proper glide path, the use of brushing action and the apical forces applied by the clinician, the use of torque-controlled endodontic motors, etc. All these differences are very difficult to evaluate, since they are mostly related to individual skills, sensitivity, and operative choices (including operative sequences and motions) during $\mathrm{Ni}-\mathrm{Ti}$ intracanal instrumentation. Ideally, all these factors should be considered when choosing and clinically using an instrument to optimize performance and minimize the risks of iatrogenic errors.

\section{References}

1. Plotino G, Grande NM, Mazza C, et al. Influence of size and taper of artificial canals on the trajectory of NiTi rotary instruments in cyclic fatigue studies. Oral Surg Oral Med Oral Pathol Oral Radiol Endod 2010;109(1):e60-e66. DOI: 10.1016/j.tripleo.2009.08.009.

2. Gambarini G, Miccoli G, Seracchiani M, et al. Fatigue resistance of new and used nickel-titanium rotary instruments: a comparative study. Clin Ter 2018;169(3):e96-e101. DOI: 10.7417/T.2018.2061.

3. Di Nardo D, Galli M, Morese A, et al. A comparative study of mechanical resistance of two reciprocating files. J Clin Exp Dent 2019;11(3):e231-e235. DOI: 10.4317/jced.55487.

4. Gambarini G, Miccoli G, Seracchiani M, et al. Role of the flat-designed surface in improving the cyclic fatigue resistance of endodontic NiTi rotary instruments. Materials 2019;12(16):e2523. DOI: 10.3390/ ma12162523.

5. AIShwaimi E. Cyclic fatigue resistance of a novel rotary file manufactured using controlled memory Ni-Ti technology compared to a file made from M-wire file. Int Endod J 2018;51(1):112-117. DOI: 10.1111/iej.12756.

6. Gambarini G, Galli M, Di Nardo D, et al. Differences in cyclic fatigue lifespan between two different heat treated NiTi endodontic rotary instruments: WaveOne Gold vs EdgeOne Fire. J Clin Exp Dent 2019;11(7):e609-e613. DOI: 10.4317/jced.55839.

(c) The Author(s). 2020 Open Access This article is distributed under the terms of the Creative Commons Attribution 4.0 International License (https://creativecommons. org/licenses/by-nc/4.0/), which permits unrestricted use, distribution, and non-commercial reproduction in any medium, provided you give appropriate credit to the original author(s) and the source, provide a link to the Creative Commons license, and indicate if changes were made. The Creative Commons Public Domain Dedication waiver (http://creativecommons.org/publicdomain/zero/1.0/) applies to the data made available in this article, unless otherwise stated. 
7. Dosanjh A, Paurazas S, Askar M. The effect of temperature on cyclic fatigue of nickel-titanium rotary endodontic instruments. J Endod 2017;43(5):823-826. DOI: 10.1016/j.joen.2016.12.026.

8. Ebihara A, Yahata Y, Miyara K, et al. Heat treatment of nickel-titanium rotary endodontic instruments: effects on bending properties and shaping abilities. Int Endod J 2011;44(9):843-849. DOI: 10.1111/j.13652591.2011.01891.x
9. Gambarini $G$, Seracchiani M, Piasecki L, et al. Measurement of torque generated during intracanal instrumentation in vivo. Int Endod J 2019;52(5):737-745. DOI: 10.1111/iej.13042.

10. Gambarini G, Piasecki L, Miccoli G, et al. Classification and cyclic fatigue evaluation of new kinematics for endodontic instruments. Aust Endod J 2019;45(2):154-162. DOI: 10.1111/aej. 12294. 